\title{
Cannabis and Young Users-A Brief Intervention to Reduce Their Consumption (CANABIC): A Cluster Randomized Controlled Trial in Primary Care
}

\author{
Catherine Laporte, $M D, \mathrm{PbD}^{1,2}$ \\ Hélène Vaillant-Roussel, MD, \\ $P b D^{1,3}$ \\ Bruno Pereira, $\mathrm{PbD}^{4}$ \\ Olivier Blanc, $M S^{1,5}$ \\ Bénédicte Eschalier, $M D^{1}$ \\ Shérazade Kinouani, $M D^{6}$ \\ Georges Brousse, $M D, P b D^{2,5}$ \\ Pierre-Michel Llorca, MD, PbD ${ }^{2,5}$ \\ Pbilippe Vorilhon, $M D^{1,7}$ \\ 'Univ Clermont 1, UFR Medicine, Depart- \\ ment of General Practice, Clermont-Fer- \\ rand, F-63001, France
}

${ }^{2}$ Univ Clermont 1, UFR Medicine, EA7280, Clermont-Ferrand, F-63001, France

${ }^{3} \mathrm{CHU}$ Clermont-Ferrand, Clinical Pharmacology Departement - Clinical Investigation Centre (Inserm CIC 501), Clermont-Ferrand, F-63003, France

${ }^{4} \mathrm{CHU}$ Clermont-Ferrand, Office for Clinical research and Innovation, Clermont-

Ferrand, F-63003, France

${ }^{5} \mathrm{CHU}$ Clermont-Ferrand, Psychiatry B, Clermont-Ferrand, F-63003, France

${ }^{6}$ Univ Bordeaux, UFR Medicine, Department of General Practice, Bordeaux, F-33076, France

${ }^{7}$ Univ Clermont 1, UFR Medecine, EA4681, Clermont-Ferrand, F-63001, France

Conflicts of interest: authors report none.

\section{CORRESPONDING AUTHOR}

Catherine Laporte, MD, $\mathrm{PhD}$

28 Place Henri Dunant, BP 38 63001 Clermont-Ferrand Cedex 1

France

Catherine.laporte@udamail.fr

\begin{abstract}
PURPOSE Brief intervention to reduce cannabis is a promising technique that could be adapted for use in primary care, but it has not been well studied in this setting. We tested the efficacy of a brief intervention conducted by general practitioners among cannabis users aged 15 to 25 years.
\end{abstract}

METHODS We performed a cluster randomized controlled trial with 77 general practitioners in France. The intervention consisted of an interview designed according to the FRAMES (feedback, responsibility, advice, menu, empathy, selfefficacy) model, while the control condition consisted of routine care.

RESULTS The general practitioners screened and followed up 261 young cannabis users. After 1 year, there was no significant difference between the intervention and control groups in the median number of joints smoked per month among all users (17.5 vs 17.5; $P=.13)$, but there was a difference in favor of the intervention among nondaily users ( 3 vs $10 ; P=.01$ ). After 6 months, the intervention was associated with a more favorable change from baseline in the number of joints smoked $(-33.3 \%$ vs $0 \%, P=.01)$ and, among users younger than age of 18 , smoking of fewer joints per month (12.5 vs $20, P=.04$ ).

CONCLUSIONS Our findings suggest that a brief intervention conducted by general practitioners with French young cannabis users does not affect use overall. They do, however, strongly support use of brief intervention for younger users and for moderate users.

Ann Fam Med 2017;15:131-139. doi: https://doi.org/10.1370/afm.2003.

\section{INTRODUCTION}

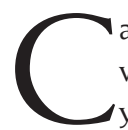
annabis is the first illegal substance used by young people worldwide. ${ }^{1}$ Across continents, $7 \%$ to $12 \%$ of adolescents and teenagers to 25 years are monthly users..$^{1-4}$ In Europe, France has the highest consumption of cannabis. ${ }^{3}$ As of 2014, 25.5\% of French adolescents (aged 15 to 17 years) and $17 \%$ of young adults (aged 18 to 25 years) were monthly users of cannabis. ${ }^{5,6}$

Current data are clear about the risks of cannabis use, ${ }^{7}$ which include social and psychiatric risks (eg, anxiety, depression, and an increased incidence of schizophrenia in vulnerable individuals) ${ }_{1}^{8,9}$ risks of lung and otorhinolaryngeal cancers, ${ }^{10,11}$ and cardiovascular risk. ${ }^{12-14}$ Use before driving increases the likelihood of motor vehicle collision-related morbidity and mortality. ${ }^{15-18}$ During adolescence, cannabis use causes cerebral microstructural changes that are not always reversible and have been implicated in cognitive and psychiatric disorders. ${ }^{19}$

In France, $80 \%$ of youth aged 15 to 25 years have visited their general practitioner in the preceding year. ${ }^{5}$ These visits could represent a privileged opportunity to identify young cannabis users and intervene to reduce their consumption. Motivational interviewing is a method of interaction centered on the patient and intended to modify behavior. ${ }^{20,21}$ Brief intervention is a 
motivational interviewing technique that is characterized by its short duration. ${ }^{22}$ It is well accepted by both adolescent ${ }^{23}$ and young adult ${ }^{24}$ cannabis users.

Many randomized controlled trials have tested the efficacy of a brief intervention addressing cannabis use in adolescents, young adults, or both. These trials involved specific populations: students attending high schools, ${ }^{25-28}$ students attending universities, ${ }^{29-31}$ people visiting addiction centers, ${ }^{32}$ people contacting the emergency services, ${ }^{33,34}$ or the general public following media calls for participation. ${ }^{35-40}$ The initial levels of consumption varied greatly, from once a year ${ }^{19}$ to weekly ${ }^{11,13,14,16}$ to monthly, ${ }^{20-22,25}$ and qualitative data suggested motivation ranged from a desire to $\operatorname{stop}^{23}$ to having dependency symptoms. ${ }^{18,24}$ Furthermore, the measured impact on use varied considerably, with some of the trials reporting a reduction in $\mathrm{use}^{13,16,21-23}$ or an increase in the number of abstainers, ${ }^{12,20,23}$ but others showing no effect. ${ }^{11,14,15,17-19,24}$

Few primary care-based studies of intervention exist in the published literature. Two trials involving US adolescents demonstrated a decrease in cannabis use (in excessive users) ${ }^{37}$ or in the desire to use (irrespective of their initial level of consumption). ${ }^{38}$ These studies were carried out in a primary care setting, but the brief intervention was not performed by a general practitioner, instead, it was carried out, for example, by a therapist with a computer or a case manager. A trial conducted among young Swiss patients who were excessive cannabis users did not find a brief intervention conducted by a general practitioner to be efficacious. ${ }^{39}$

More research is therefore needed to assess the efficacy of a brief intervention for the reduction of cannabis use in primary care. ${ }^{40,41}$ We hypothesized that a brief intervention conducted in primary care by general practitioners among young users aged 15 to 25 years, regardless of their initial level of consumption, would lead to a decrease in their consumption at 1 year relative to usual care.

\section{METHODS}

\section{Study Design}

We used a pragmatic cluster randomized trial to test the efficacy of a brief intervention, conducted by general practitioners in primary care practices, in reducing the consumption of cannabis among young users. Cluster randomization was appropriate for limiting contamination bias, ${ }^{42}$ as allocating patients from the same practice into 2 different experimental groups could introduce bias. After being trained in the motivational interview method, a general practitioner was deemed unable to have a neutral visit with patients, and so could not care for patients in the control group. The design and study protocol have been published previously. ${ }^{43}$

\section{Setting and Participants}

All general practitioners working in general practices in 3 areas of France (Auvergne, Rhône-Alpes, and Languedoc-Roussillon) were personally invited by mail to take part in the trial. Their addresses were sourced from the National Institute for Statistics and Economic Studies. General practitioners who had specialized training in addiction treatment (eg, a university degree, qualification, or university course) were excluded from the trial.

All cannabis users aged 15 to 25 years who had consumed at least 1 joint per month for at least 1 year were eligible for inclusion in the study. We excluded patients who had severe mental disorders (that had been diagnosed by a psychiatrist before the study); had previously been treated for withdrawal from addiction; had a poor command of the French language; or had participated in a preliminary study of adolescent cannabis users. ${ }^{44}$

\section{Randomization and Blinding}

CANnabis and Adolescents, a Brief Intervention to Reduce Their Consumption (CANABIC) was a cluster randomized controlled clinical trial in which the general practice was the unit of randomization. The unit of observation of the outcome was the patient enrolled in the study. General practitioners from the same practice were allocated to the same group to avoid contamination bias. All patients of a given general practitioner were assigned to his or her group. Randomization and allocation were carried out by an independent statistician in each area using Stata version 13 (StataCorp LP).

\section{Study Procedure}

The study was proposed to general practitioners between October and December 2011. From those who were eligible and volunteered, we randomly selected 50 per region. They were randomized into the intervention group or the control group. In the intervention group, we trained the general practitioners in conducting the brief intervention; in the control group, they simply received a briefing on the study. All general practitioners then had 1 year during which to enroll the first 5 eligible patients seen in their practice, regardless of the reason for the visit. Patients were seen alone during the visit. During this initial enrollment visit, the general practitioners in the intervention group conducted the brief intervention. In both groups, the general practitioners conducted follow-up visits at 3,6, and 12 months. Those in the intervention group carried out the brief intervention at each visit, whereas those in the 
control group gave routine care. In both groups, general practitioners were paid $€ 80$ per patient enrolled; patients were not paid.

\section{Intervention and Control Groups}

The general practitioners in the intervention group conducted an interview according to the brief intervention model, defined by the acronym FRAMES (feedback, responsibility, advice, menu, empathy, self-efficacy). ${ }^{22}$ During feedback, they related to the patient the quantity of their consumption and its consequences, then focused on their personal responsibility to change. The general practitioners gave advice about moderation and established a menu of alternative change options with the patient. They adopted an empathetic style, without judgment. Finally, they encouraged patient self-efficacy.

The general practitioners were trained to carry out the brief intervention through a training day that was held in collaboration with an addiction specialist and a psychologist specializing in addiction, and was approved by the Collège National des Généralistes Enseignants (National College of General Teachers). It aimed to update general practitioners' knowledge about cannabis, remove communication barriers, and train them in the brief intervention. Learning activities included discussion of the results of preliminary studies and role-play exercises about the brief intervention. The general practitioners had the flexibility to adapt the brief intervention according to their patients' needs. The study team did not monitor the brief intervention conducted by the general practitioners.

In the control group, after assessing patients' cannabis use, the general practitioners administered routine care. General practitioners and patients were told that they were participating in an observational descriptive study about cannabis use.

\section{Measures}

At each patient visit, general practitioners recorded the number of joints and bongs smoked, the quantity of alcohol and cigarettes consumed, and experimentation with other drugs. At baseline and at the end of the trial, all patients completed an anonymous self-administered questionnaire. They provided the same information as given to the general practitioner, but also details about how they used marijuana and their perception of their consumption. At baseline, the self-administered questionnaire contained questions from the Cannabis Abuse Screening Trial (CAST) tool ${ }^{45}$ to identify at-risk users.

\section{Outcomes}

The trial's primary outcome was the number of joints consumed per month at 1 year. The secondary out- comes were the number of joints consumed per month at the intermediate time points, and the quantities of cigarettes and alcohol concomitantly consumed. We also compared outcomes for those who were, and were not, daily users initially, as well as for patients aged younger than 18 years and those aged 18 years and older.

\section{Sample Size}

The sample size estimation and statistical analyses have been previously reported. ${ }^{43}$ To establish the significance of any differences in outcomes between the 2 groups, we required 250 patients, as detailed below. The working hypotheses of this study were (1) that the intervention would reduce by $30 \%$ the stated consumption of cannabis at 12 months (ie, 5 joints per month) and (2) that a Hawthorne effect would occur, whereby simply participating in the study would reduce use. ${ }^{46}$ Our projection was that patients in the control group would reduce their consumption by $15 \%$.

Various simulations were carried out according to the standard deviation (SD) of joint consumption (an $\mathrm{SD}$ of $1.5,2,3,4$, or 5 joints) and clustering by practice (an intracluster correlation coefficient [ICC] of 0.05 to 0.2 ). Considering the results of these simulations-a 2-sided type I error of $\alpha=0.05$, a statistical power equal to $90 \%$, a $10 \%$ general practitioner dropout rate, and a $20 \%$ patient dropout rate-we calculated that a minimum of 250 patients were required to detect a relative difference in the reduction in joint consumption of $50 \%$ between the 2 groups ( $30 \%$ vs $15 \%$ ). As each general practitioner had to enroll 5 adolescents and young adults, a total of 50 general practitioners were needed to attain our goal of 250 patients.

\section{Statistical Methods}

All statistical analyses were performed using Stata version 13 . The tests were 2 -sided with type I error set at $\alpha=0.05$. Baseline characteristics were presented as means \pm SDs or medians (interquartile ranges) according to the statistical distribution of continuous data, and as number of patients and percentages for categorical parameters. At baseline, we compared patient characteristics between the randomized groups using the Student $t$ test, or the Mann-Whitney test if the conditions of the $t$ test were not met (normality and homoscedasticity determined using the FisherSnedecor test). For categorical variables, comparisons between groups were performed using the $\chi^{2}$ test or, when appropriate, the Fisher exact test. Hierarchical linear regression models (mixed models) with levels per practice, individuals within practices, and repeated measurements per individual were generated to estimate the effects of the intervention on the number 
of joints smoked per month at various follow-up time points. We assessed the normality of the residuals using the Shapiro-Wilk test. According to the skewness of the statistical distribution of the primary outcome, these models were run using the logarithm of the number of joints (to achieve the normality of the dependent variable). These models included an interaction between the randomization group and time point, and were adjusted for the number of joints smoked per month at baseline, age of first consumption, sex, CAST score at baseline, socioeconomic status, and general practitioner characteristics. ICCs were calculated by group. Subgroup analyses with the relevant age and level of initial consumption were performed after the assessment of a fixed-effect interaction (subgroup $\times$ randomization group). When appropriate $(P<.05)$, a subgroup analysis was performed. We took into account missing data by using estimation methods. ${ }^{47}$ We chose to report all the individual $P$ values without carrying out any mathematical correction for distinct tests comparing groups. ${ }^{48}$ In particular, we focused on the magnitude of differences and their clinical relevance. ${ }^{49}$ The self-administered questionnaire allowed us to determine the number of joints consumed per month anonymously; therefore, it was possible to calculate the Lin concordance ${ }^{50}$ with our data for the principal criteria.

\section{Ethics Considerations}

The trial protocol was approved by the Comité de Protection des Personnes SUD-EST VI (SouthEast VI Committee for the Protection of Persons) of ClermontFerrand. The patients were given written information about the study. Enrollment was voluntary, anonymous, and within medical confidentiality, and it ensured an unconditional right to withdrawal. In accordance with French law, general practitioners have signed a form of nonopposition of patients, allowing minors to participate without parental consent.

\section{RESULTS}

\section{Recruitment and Follow-up}

Figure 1 shows recruitment and flow of trial participants. In all, 77 general practitioners enrolled 262 patients and followed them up between March 2012 and March 2014.

\section{Baseline Characteristics}

Baseline characteristics of the 77 general practitioners in the intervention and control groups were similar (Table 1). They were 48 years old, on average $e_{i}$ a slight majority were male, and most worked in urban or semirural areas.

The sociodemographic characteristics of the patients in the 2 groups were also generally comparable (Table 1). The intervention group contained more bong users than the control group $(19.2 \%$ vs $9.9 \% ; P=.04)$.

\section{Figure 1. Flowchart of general practitioners and patients.}

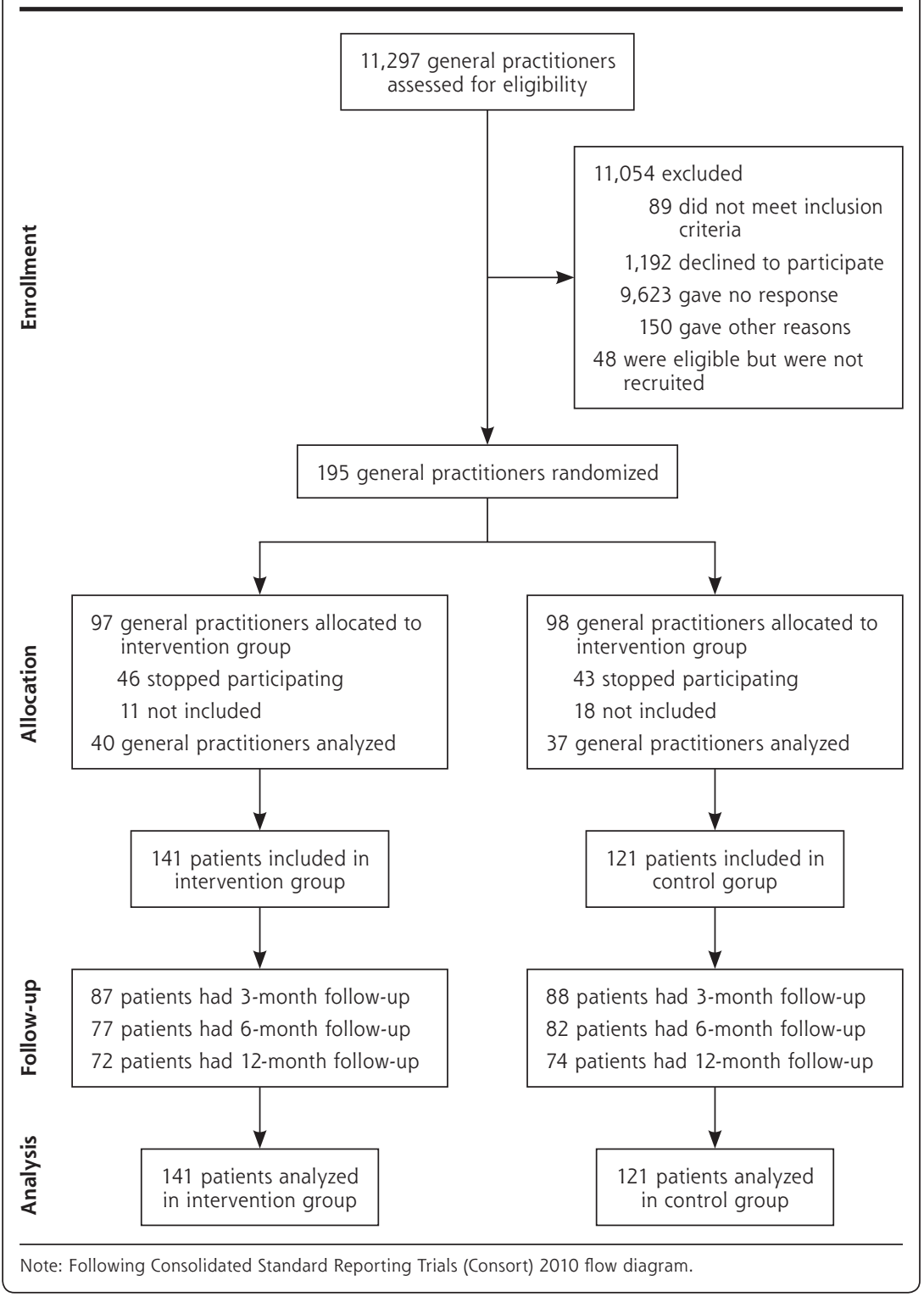


On the self-administered questionnaire at baseline, the median number of joints smoked per month was 20 joints for the patients overall (range, 5 to 50 ). This number was essentially the same as the 20 (range, 6 to 60) reported by patients to their physician, with a Lin concordance coefficient of 0.9 .

\section{Delivery and Receipt of the Intervention}

Of the 262 patients enrolled, 175 of them $(66.8 \%)$ had follow-up at 3 months, $159(60.7 \%)$ at 6 months, and $146(55.7 \%)$ at 12 months. On average, each patient had $2.8( \pm 1.2)$ visits.

\section{Primary Outcome}

The brief intervention and control groups did not differ significantly at any of the time points with respect to the primary outcome of number of joints smoked per month (Figure 2). After 1 year, the median number of joints consumed monthly was identical at 17.5 (2 to $60)$ in the intervention group and 17.5 (4 to 40 ) in the control group $(P=.13)$. Additionally, when all time points were combined, there was no global effect $(P=.11)$.

The intervention group did, however, have a significant reduction from baseline in the number of joints consumed at both 6 months $(P=.01)$ and 12 months $(P=.02)$.

Furthermore, the number of joints consumed at 6 months fell in the intervention group but remained unchanged in the control group $(-33.3 \%$ vs $0 \% ; P=.01)$.

The ICC was 0.02 overall (0.12 in the intervention group, 0.01 in the control group). In the per-protocol analysis, monthly joint consumption at baseline was greater among the 72 patients in the brief intervention group (30 [7 to 85$])$ than among the 74 patients in the control group (18 [5 to 32$])(P=.04)$, but there was no significant difference at 12 months (17.5 [2 to 60$]$ vs 17.5 [4 to 40$])$ $(P=.47)$.

\section{Secondary Outcomes}

\section{Subgroup Analyses}

In a subgroup analysis according to frequency of cannabis use at baseline, among nondaily cannabis users,
Table 1. Characteristics of General Practitioners and Patients

\begin{tabular}{|c|c|c|c|c|}
\hline \multirow[b]{2}{*}{ Characteristic } & \multirow[b]{2}{*}{ Overall } & \multicolumn{2}{|c|}{ Group } & \multirow{2}{*}{$\begin{array}{c}P \\
\text { Value }\end{array}$} \\
\hline & & Intervention & Control & \\
\hline General practitioners, No. & 77 & 40 & 37 & \\
\hline Men, No. (\%) & $42(54.6)$ & $23(57.5)$ & $19(51.3)$ & .59 \\
\hline Age, mean (SD), y & $48.3(9.2)$ & $47.8(9.0)$ & $48.9(9.5)$ & .60 \\
\hline Group practice, No. (\%)a & $51(66.2)$ & $27(67.5)$ & $24(64.9)$ & .81 \\
\hline Self-employed, No. (\%) & $65(85.5)$ & $32(82.1)$ & $33(89.2)$ & .38 \\
\hline Teaching role, No. $(\%)^{b}$ & $32(41.6)$ & $18(45.0)$ & $14(37.9)$ & .52 \\
\hline \multicolumn{5}{|l|}{ Work setting } \\
\hline Rural, No. (\%) & $9(11.7)$ & $4(10.0)$ & $5(13.5)$ & .73 \\
\hline Semirural, No. (\%) & $37(48.0)$ & $18(45.0)$ & 19 (51.4) & \\
\hline Urban, No. (\%) & $31(40.3)$ & $18(45.0)$ & $13(35.1)$ & \\
\hline $\begin{array}{l}\text { Number of patients enrolled, } \\
\text { mean (SD) }\end{array}$ & $3.4(2.1)$ & $3.5(2.2)$ & $3.3(2.0)$ & .60 \\
\hline Patients, No. & 262 & 141 & 121 & \\
\hline Men, No. (\%) & $169(64.5)$ & $89(63.1)$ & $80(66.1)$ & .61 \\
\hline \multicolumn{5}{|l|}{ Age } \\
\hline Mean (SD), y & $20.60(2.6)$ & $20.88(2.7)$ & $20.28(2.6)$ & .07 \\
\hline$<18$ y, No. (\%) & $47(18.0)$ & $20(14.3)$ & $27(22.3)$ & .09 \\
\hline \multicolumn{5}{|l|}{ Marital status, No. (\%) } \\
\hline Single & $211(81.2)$ & $108(77.7)$ & $103(84.3)$ & .31 \\
\hline Married & $49(18.9)$ & $31(22.3)$ & $18(14.9)$ & \\
\hline Divorced/separated & $2(0.8)$ & $1(0.7)$ & $1(0.9)$ & \\
\hline \multicolumn{5}{|l|}{ Lodging status, No. (\%) } \\
\hline Cohabiting & $202(77.1)$ & $106(75.2)$ & $96(79.3)$ & .42 \\
\hline Living alone & $63(24.1)$ & $37(26.2)$ & $26(21.5)$ & .37 \\
\hline \multicolumn{5}{|l|}{ Employment status, No. (\%) } \\
\hline Working & $147(56.1)$ & $82(58.2)$ & $65(53.7)$ & .07 \\
\hline No occupation & $7(2.7)$ & $5(3.6)$ & $2(1.7)$ & \\
\hline Student & $108(41.2)$ & $54(38.3)$ & $54(44.6)$ & \\
\hline $\begin{array}{l}\text { Psychotropic medication use, } \\
\text { No. }(\%)^{c}\end{array}$ & $10(3.8)$ & $6(4.3)$ & $4(3.3)$ & .69 \\
\hline \multicolumn{5}{|l|}{ Cannabis use } \\
\hline Joints per mo, median (IQR) & $20(6-60)$ & $30(6-80)$ & $20(5-40)$ & .08 \\
\hline$\geq 30$ joints per mo, No. (\%) & $121(46.2)$ & $73(51.8)$ & $48(39.7)$ & .05 \\
\hline Use bongs, No. (\%) & $39(14.9)$ & $27(19.2)$ & $12(9.9)$ & .04 \\
\hline Age at first use, mean (SD), y & $15.15(1.9)$ & $15.24(2.1)$ & $15.04(1.6)$ & .40 \\
\hline \multicolumn{5}{|l|}{ Alcohol use } \\
\hline Used in past month, No. (\%) & $204(77.9)$ & $110(78.0)$ & $94(77.7)$ & .94 \\
\hline $\begin{array}{l}\text { Quantity: glasses/wk, median } \\
\text { (IQR) }\end{array}$ & $6(2-10)$ & $5(2-10)$ & $7.5(3-14)$ & .02 \\
\hline \multicolumn{5}{|l|}{ Tobacco use } \\
\hline Used in past month, No. (\%) & $240(91.6)$ & $124(87.9)$ & $116(95.7)$ & .02 \\
\hline $\begin{array}{l}\text { Quantity: cigarettes/wk, } \\
\text { median (IQR) }\end{array}$ & $60(30-82)$ & $60(35-100)$ & $60(28-78)$ & .60 \\
\hline $\begin{array}{l}\text { Experimented with other } \\
\text { drugs, No. (\%) }\end{array}$ & $111(42.4)$ & $59(41.8)$ & $52(43.0)$ & .85 \\
\hline \multicolumn{5}{|l|}{$\mathrm{IQR}=$ interquartile range. } \\
\hline $\begin{array}{l}\text { any practice other than solo practice } \\
{ }^{\mathrm{b}} \text { Taught students in his or her practic } \\
\text { ' Anxiolytics prescribed by the genera }\end{array}$ & titioner. & & & \\
\hline
\end{tabular}


median monthly joint consumption after 1 year was significantly lower in the brief intervention group than in the control group (3 vs 10 joints; $P=.01$ ) (Table 2 ). In contrast, the difference among daily users was not significant (55 vs $30 ; P=.40$ ). The results of the multivariate analysis, adjusted for sex and age, confirmed these results.

The subgroup analysis according to age, with a multivariate model considering the interaction age $\times$ group, showed that among users younger than 18 years, those in the brief intervention group had significantly lower monthly cannabis use than peers in the control group at 6 months (12.5 vs 20 joints; $P=.04$ ) (Figure 3 ). Also, in this subset, the proportion of daily users at 12 months was lower in the intervention group $(4[26.7 \%])$ than in the control group $(10[55.6 \%])(P=.04)$, whereas there was no difference among users aged 18 years or older (27 [47.4\%] vs $21[37.5 \%])(P=.46)$. users younger than 18 years, the intervention reduced the quantity used compared with routine care.

\section{Comparison With Published Data}

In our study, cannabis use fell in both groups, without statistical difference. A Swiss cluster randomized trial in primary care had the same result. ${ }^{39}$ The Haw thorne effect may partially explain these findings. ${ }^{46}$ Seeing a patient regularly during a study can modify the behavior of both the patient and the general practitioner. ${ }^{51,52}$ In our study, we observed a significant decrease in cannabis use in both the intervention group and control group among patients aged 18 years and older. Among patients younger than 18 years, however, consumption decreased in the intervention group but increased in the control group, with a significant difference at 6 months, consistent with another trial conducted in primary care. ${ }^{43}$

\section{Use of Other Substances}

The lower proportion of tobacco smokers at baseline in the brief intervention group vs the control group persisted at 12 months (77.8\% vs $90.5 \% ; P=.03)$. There was no significant difference between groups in the number of glasses of alcohol consumed per week at 12 months ( 4 [2 to 7] vs 6 [2 to 10 ]; $P=.17)$.

\section{DISCUSSION}

\section{Main Findings}

Our trial is one of only a handful to test a brief intervention performed by general practitioners for young cannabis users in primary care. The main results can be summarized as follows: (1) after 1 year, the intervention was associated with a decrease in the median number of joints smoked per month, but without significant difference relative to routine care, (2) among nondaily users, the intervention significantly reduced use of cannabis compared with routine care $;$ (3) after 6 months, the change in median number of joints smoked per month was larger with the intervention than with routine care; and (4) among cannabis
Figure 2. Median number of joints smoked per month at baseline and at 3, 6, and 12 months.

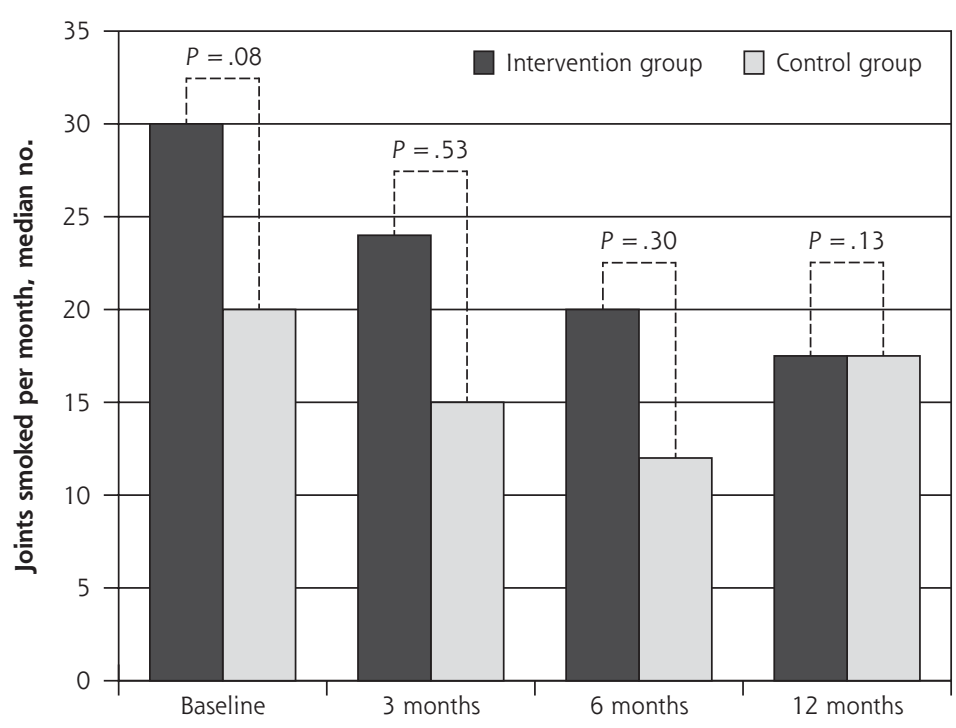

\begin{tabular}{|c|c|c|c|c|}
\hline & \multicolumn{4}{|c|}{ Intragroup comparison vs baseline ${ }^{a}$} \\
\hline & Baseline & 3 months & 6 months & 12 months \\
\hline Intervention group & $30(6-80)$ & $\begin{array}{c}24(4-60) \\
P=.08\end{array}$ & $\begin{array}{c}20(5-50) \\
P=.01\end{array}$ & $\begin{array}{c}17.5(2-60) \\
P=.02\end{array}$ \\
\hline \multirow[t]{3}{*}{ Control group } & $20(5-40)$ & $\begin{array}{c}15(5-35) \\
P=.31\end{array}$ & $\begin{array}{c}12(5-30) \\
P=.30\end{array}$ & $\begin{array}{c}17.5(4-40) \\
P=.29\end{array}$ \\
\hline & \multicolumn{4}{|c|}{ Intergroup comparison of change from baseline } \\
\hline & & 3 months & 6 months & 12 months \\
\hline Intervention group & - & $\begin{array}{c}-17 \% \\
(-67 \% \text { to } 20 \%)\end{array}$ & $\begin{array}{c}-33.3 \% \\
(-6.25 \% \text { to } 0 \%)\end{array}$ & $\begin{array}{c}-33.3 \% \\
(-90 \% \text { to } 20 \%)\end{array}$ \\
\hline Control group & - & $\begin{array}{c}0 \% \\
(-50 \% \text { to } 67 \%) \\
P=.19\end{array}$ & $\begin{array}{c}0 \% \\
(-50 \% \text { to } 89 \%) \\
P=.01\end{array}$ & $\begin{array}{c}-3 \% \\
(-67 \% \text { to } 150 \%) \\
P=.09\end{array}$ \\
\hline
\end{tabular}


This pattern suggests that brief intervention may be effective in slowing or preventing increases in use, which often occur between 15 and 25 years of age. ${ }^{53}$ The impact on adolescents can be explained by their ambivalence in this period. The general practitioner is perceived both as a potential informer and as a benevolent authority. ${ }^{44}$

\section{Table 2. Comparison of Intervention and Control Groups According to Frequency of Cannabis Use at Baseline}

\begin{tabular}{|c|c|c|c|c|c|c|}
\hline \multirow[b]{2}{*}{ Time Point } & \multicolumn{3}{|c|}{ Nondaily Users ${ }^{a}$} & \multicolumn{3}{|c|}{ Daily Users ${ }^{b}$} \\
\hline & Intervention & Control & $\begin{array}{c}P \\
\text { Value }\end{array}$ & Intervention & Control & $\begin{array}{c}P \\
\text { Value }\end{array}$ \\
\hline Baseline & $6(4-14)$ & $10(4-15)$ & .29 & $70(40-120)$ & $50(30-95)$ & .11 \\
\hline 3 months & $4(2-20)$ & $10(5-21)$ & .19 & $40(20-95)$ & $35(10-60)$ & .41 \\
\hline 6 months & $5(1-10)$ & $10(5-20)$ & .002 & $40(23-100)$ & $30(10-68)$ & .17 \\
\hline 12 months & $3(0-15)$ & $10(3-30)$ & .01 & $55(10-100)$ & $30(15-60)$ & .40 \\
\hline \multicolumn{7}{|c|}{ Note: Values are median number of joints smoked per month (interquartile range). } \\
\hline \multicolumn{7}{|c|}{$\begin{array}{l}\text { a Smoked }<30 \text { joints per month at baseline. } \\
\text { b Smoked } \geq 30 \text { joints per month at baseline. }\end{array}$} \\
\hline
\end{tabular}

Figure 3. Median number of joints smoked per month at baseline and at 3,6 , and 12 months, according to age-group.

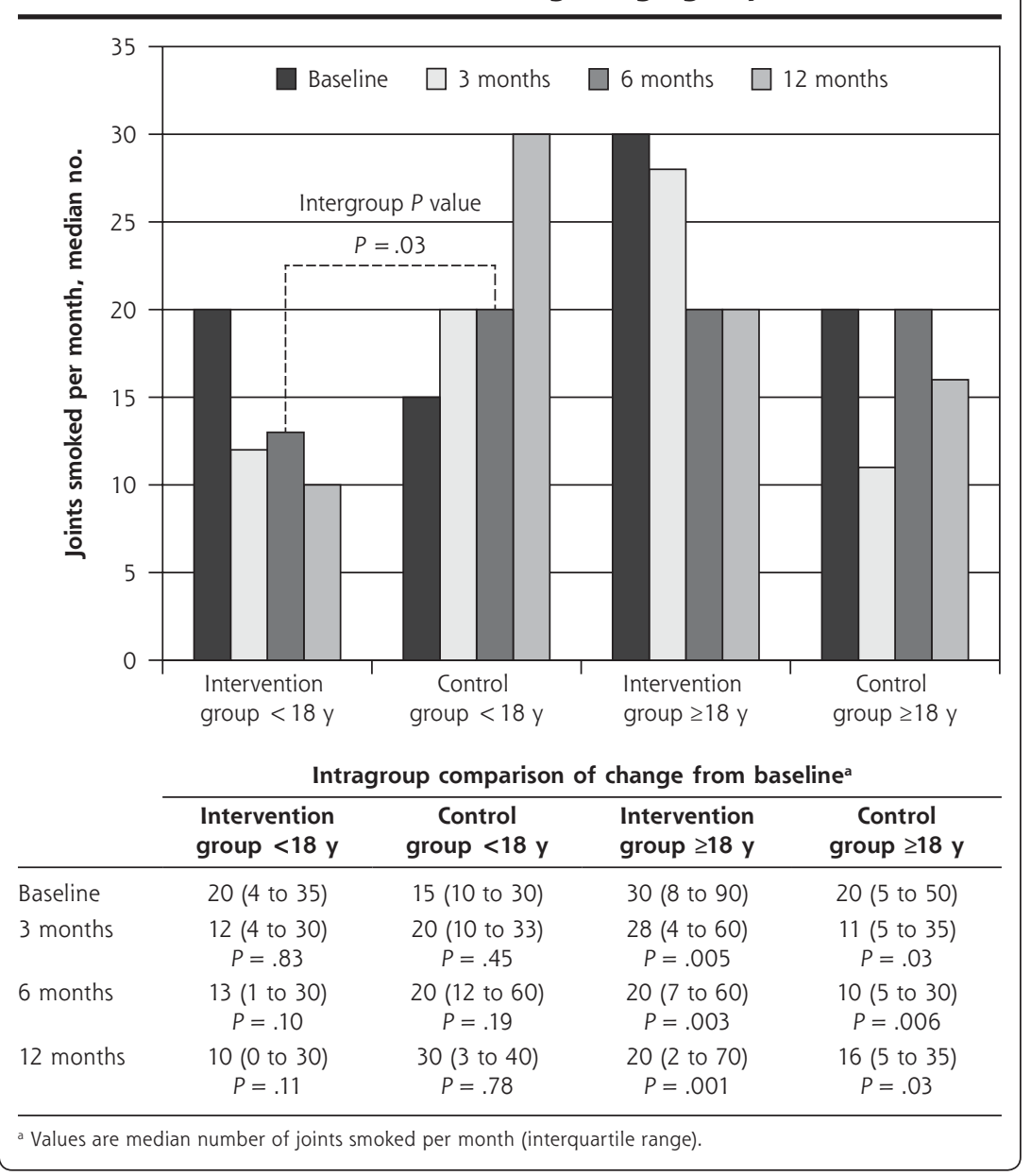

Our brief intervention also had an effect on nondaily users, consistent with findings of another study conducted in primary care. ${ }^{38}$ Brief intervention has likewise proven effective in nonexcessive drinkers. ${ }^{54,55}$ There may be a neurophysiologic explanation. The effectiveness of brief interventions is based on patients' ability to change after realizing the adverse effects related to a substance. It appeals to their executive functions. In cases of dependency, increased salience and difficulty in accepting the adverse effects may necessitate longer motivational methods. ${ }^{56}$

\section{Strengths and Limitations}

Of the 195 randomized general practitioners, only 77 ultimately enrolled patients. Those who did not were not significantly different from those who did, so such differences were unlikely to cause major recruitment bias. The power of the study may have been affected, although the required number of patients was reached. The rate of follow-up was lower than that of the Swiss trial. ${ }^{39}$ Administrative burden and a lack of time were the main obstacles reported by general practitioners to enrollment and follow-up of patients, ${ }^{57}$ and also to their identification..$^{58}$

In our trial, the general practitioners conducted screening, enrollment, intervention, and data collection, which may have introduced bias, but these practices reflect the real-life course of patient care, and the situation was the same in both groups. The double collection of data (both by the physician during the visit and by anonymous self-report) ensured good reliability. For the same reasons, performance of the general practitioners in delivering the brief intervention was not evaluated.

This study contributes to the discussion on intravariability and intervariability of general practitioners in response to an intervention, as well as on the effects of interventions on individuals, the 
study of whom requires mixed methods: qualitative and quantitative. ${ }^{59}$ The impact of an intervention could be unexpected (worse than expected or even harmful). ${ }^{60}$ It would be pertinent to analyze the behavior within each group to understand such changes, as was done in a recent cluster study. ${ }^{61}$ We integrated characteristics of the general practitioners into our analysis, and are further evaluating patients' behavior according to these characteristics and the practitioners' practices. This analysis of behavior of each cluster in a clustered response test is one of the challenges of research in primary care..$^{59}$

\section{Implications}

In conclusion, our study did not show an effect on cannabis use of a brief intervention conducted by general practitioners with French adolescents and young adult cannabis users overall. Our results do, however, strongly support use of brief interventions for users who are younger than age 18 and for moderate, nondaily users.

To read or post commentaries in response to this article, see it online at http://www.annfammed.org/content/15/2/131.

Key words: general practice; addiction; marijuana; brief intervention; public health; primary care; practice-based research

Submitted January 7, 2016; submitted, revised, July 5, 2016; accepted July 28, 2016.

Funding support: This study was supported by a grant from the French Ministry of Health (PHRC-Hospital Program of Clinical Research; No. 0505, 2011).

Disclaimer: The sponsor had no role in the study.

Previous presentations: This research was presented in part at the National Congress of General Medicine, 2015, Paris, France, and at the National Congress of Teaching GPs, 2014, Lille, France.

Trial registration: Clinicaltrials.gov Identifier: NCT01433692.

Acknowledgments: We wish to thank the patients and general practitioners who participated in the study. We also thank the Departments of General Medicine that collaborated on the project: Grenoble, SaintEtienne, and Montpellier. We thank the members of the Scientific Committee whom we consulted at key stages of the study: Bruno Falissard, MD, PhD, Faculty of Medicine of South-Paris; Amine Benyamina, MD, PhD, CHU Paul Brousse; Jean-Pierre Lebeau, MD, Faculty of Medicine of Tours; Luc Martinez, MD, Faculty of Medicine of Paris VI; and Nicolas Authier, MD, PhD, CHU Clermont-Ferrand. We wish to thank Pierre-Louis Druais, MD, Faculty of Medicine of Paris V, and Claude Dubray, MD, $\mathrm{PhD}, \mathrm{CHU}$ Clermont-Ferrand, for their help in project feasibility.

\section{References}

1. United Nations Office on Drugs and Crime. World Drug Report 2015. New York, NY: United Nations; 2015. https://www.unodc.org/documents/wdr2015/WDR15_ExSum_F.pdf. Accessed Oct 28, 2016.

2. Hedded SL, Kennet J, Lipari R, Medley G, Tice P. Behavioral Health Trends in the United States: Results from the 2014 National Survey on Drug Use and Health. Rockville, MD: Center for Behavioral Health Statistics and Quality, Substance Abuse and Mental Health Services Administration; 2015.
3. European Monitoring Center for Drugs and Drug Addiction (EMCDDA). European Drug Report: Trends and Developments. Lisbon, Portugal: European Monitoring Center for Drugs and Drug Addiction; 2014.

4. Rotermann M, Langlois K. Prévalence et corrélats de la consommation de marijuana au Canada, 2012. Rapports sur la santé. 2015; 26(4):11-16.

5. Institut National de Prévention et d'Education pour la Santé (INPES). Baromètre de santé 2014. http://inpes.santepubliquefrance.fr/30000/ actus2015/013-tabac-donnees-barometre-2014.asp. Published 2015. Accessed Oct 28, 2016.

6. Spilka S, Le Nezet O, Ngantcha M, Beck F. Les drogues à 17 ans: analyse de l'enquête Enquête sur la Santé et les Consommations lors de l'Appel de Préparation À la Défense (ESCAPAD). OFDT (Observatoire Français des Drogues et Toxicomanies). http://www.ofdt.fr/ statistiques-et-infographie/sources-statistiques/enquete-sur-la-santeet-les-consommations-lors-de-la-journee-dappel-et-de-preparation-ladefense-escapad-alcool/. Published 2014. Accessed Oct 28, 2016.

7. Hall W, Degenhardt L. Adverse health effects of non-medical cannabis use. Lancet. 2009;374(9698):1383-1391.

8. Macleod J, Oakes R, Copello A, et al. Psychological and social sequelae of cannabis and other illicit drug use by young people: a systematic review of longitudinal, general population studies. Lancet. 2004;363(9421):1579-1588.

9. Moore THM, Zammit S, Lingford-Hughes A, et al. Cannabis use and risk of psychotic or affective mental health outcomes: a systematic review. Lancet. 2007;370(9584):319-328.

10. de Carvalho MFF, Dourado MR, Fernandes IB, Araújo CTP, Mesquita AT, Ramos-Jorge ML. Head and neck cancer among marijuana users: a meta-analysis of matched case-control studies. Arch Oral Biol. 2015;60(12):1750-1755.

11. Zhang LR, Morgenstern H, Greenland S, et al. Cannabis smoking and lung cancer risk: pooled analysis in the International Lung Cancer Consortium. Int J Cancer. 2015;136(4):894-903.

12. Mukamal KJ, Maclure M, Muller JE, Mittleman MA. An exploratory prospective study of marijuana use and mortality following acute myocardial infarction. Am Heart J. 2008;155(3):465-470.

13. Frost L, Mostofsky E, Rosenbloom JI, Mukamal KJ, Mittleman MA. Marijuana use and long-term mortality among survivors of acute myocardial infarction. Am Heart J. 2013;165(2):170-175.

14. Renard D, Taieb G, Gras-Combe G, Labauge P. Cannabis-related myocardial infarction and cardioembolic stroke. J Stroke Cerebrovasc Dis. 2012;21(1):82-83.

15. Gerberich SG, Sidney S, Braun BL, Tekawa IS, Tolan KK, Quesenberry CP. Marijuana use and injury events resulting in hospitalization. Ann Epidemiol. 2003;13(4):230-237.

16. Mura $P$, Kintz $P$, Ludes $B$, et al. Comparison of the prevalence of alcohol, cannabis and other drugs between 900 injured drivers and 900 control subjects: results of a French collaborative study. Forensic Sci Int. 2003;133(1-2):79-85.

17. Grotenhermen F, Leson G, Berghaus G, et al. Developing limits for driving under cannabis. Addiction. 2007;102(12):1910-1917.

18. Drummer $\mathrm{OH}$, Gerostamoulos J, Batziris $\mathrm{H}$, et al. The involvement of drugs in drivers of motor vehicles killed in Australian road traffic crashes. Accid Anal Prev. 2004;36(2):239-248.

19. Renard J, Krebs M-O, Le Pen G, Jay TM. Long-term consequences of adolescent cannabinoid exposure in adult psychopathology. Front Neurosci. 2014;8:361.

20. Miller WR. Motivational interviewing: research, practice, and puzzles. Addict Behav. 1996;21(6):835-842.

21. Miller WR, Rollnick S. Motivational Interviewing: Preparing People for Change. 2nd ed. New York, NY: Guilford Press; 2002.

22. Miller WR, Sanchez VC. Motivating young adults for treatment and lifestyle change. In: Howard G, ed. Issues in Alcohol Use and Misuse in Young Adults. South Bend, IN: University of Notre Dame Press; 1993:55-82. 
23. Martin G, Copeland J, Swift W. The Adolescent Cannabis Check-Up: feasibility of a brief intervention for young cannabis users. J Subst Abuse Treat. 2005;29(3):207-213.

24. Fischer B, Dawe M, McGuire F, et al. Feasibility and impact of brief interventions for frequent cannabis users in Canada. J Subst Abuse Treat. 2013;44(1):132-138.

25. McCambridge J, Slym RL, Strang J. Randomized controlled trial of motivational interviewing compared with drug information and advice for early intervention among young cannabis users. Addiction. 2008;103(11):1809-1818.

26. Winters KC, Lee $S$, Botzet $A$, Fahnhorst $T$, Nicholson A. One-year outcomes and mediators of a brief intervention for drug abusing adolescents. Psychol Addict Behav. 2014;28(2):464-474.

27. Walker DD, Stephens R, Roffman R, et al. Randomized controlled trial of motivational enhancement therapy with nontreatmentseeking adolescent cannabis users: a further test of the teen marijuana check-up. Psychol Addict Behav. 2011;25(3):474-484.

28. Gray E, McCambridge J, Strang J. The effectiveness of motivational interviewing delivered by youth workers in reducing drinking, cigarette and cannabis smoking among young people: quasiexperimental pilot study. Alcohol Alcohol. 2005;40(6):535-539.

29. Lee CM, Kilmer JR, Neighbors C, et al. Indicated prevention for college student marijuana use: a randomized controlled trial. J Consult Clin Psychol. 2013;81(4):702-709.

30. Fischer B, Jones W, Shuper P, Rehm J. 12-month follow-up of an exploratory brief intervention for high-frequency cannabis users among Canadian university students. Subst Abuse Treat Prev Policy. 2012;7:15.

31. White HR, Morgan TJ, Pugh LA, Celinska K, Labouvie EW, Pandina RJ. Evaluating two brief substance-use interventions for mandated college students. J Stud Alcohol. 2006;67(2):309-317.

32. Dennis M, Godley SH, Diamond G, et al. The Cannabis Youth Treatment (CYT) Study: main findings from two randomized trials. J Subst Abuse Treat. 2004;27(3):197-213.

33. Woolard R, Baird J, Longabaugh R, et al. Project Reduce: reducing alcohol and marijuana misuse. Effects of a brief intervention in the emergency department. Addict Behav. 2013;38(3):1732-1739.

34. Bernstein E, Edwards E, Dorfman D, Heeren T, Bliss C, Bernstein J. Screening and brief intervention to reduce marijuana use among youth and young adults in a pediatric emergency department. Acad Emerg Med. 2009;16(11):1174-1185.

35. de Dios MA, Herman DS, Britton WB, Hagerty CE, Anderson BJ, Stein MD. Motivational and mindfulness intervention for young adult female marijuana users. J Subst Abuse Treat. 2012;42(1):56-64.

36. Stein MD, Hagerty CE, Herman DS, Phipps MG, Anderson BJ. A brief marijuana intervention for non-treatment-seeking young adult women. J Subst Abuse Treat. 2011;40(2):189-198.

37. D'Amico EJ, Miles JNV, Stern SA, Meredith LS. Brief motivational interviewing for teens at risk of substance use consequences: a randomized pilot study in a primary care clinic. J Subst Abuse Treat. 2008;35(1):53-61.

38. Walton MA, Bohnert K, Resko S, et al. Computer and therapist based brief interventions among cannabis-using adolescents presenting to primary care: one year outcomes. Drug Alcohol Depend. 2013;132(3):646-653.

39. Haller DM, Meynard A, Lefebvre D, Ukoumunne OC, Narring F, Broers $B$. Effectiveness of training family physicians to deliver a brief intervention to address excessive substance use among young patients: a cluster randomized controlled trial. CMAJ. 2014;186(8): E263-E272.

40. Hingson R, Compton WM. Screening and brief intervention and referral to treatment for drug use in primary care: back to the drawing board. JAMA. 2014;312(5):488-489.

41. Young MM, Stevens A, Galipeau J, et al. Effectiveness of brief interventions as part of the Screening, Brief Intervention and Referral to Treatment (SBIRT) model for reducing the nonmedical use of psychoactive substances: a systematic review. Syst Rev. 2014;3:50.
42. Donner A, Klar N. Issues in the meta-analysis of cluster randomized trials. Stat Med. 2002;21(19):2971-2980.

43. Laporte C, Vaillant-Roussel H, Pereira B, et al. CANABIC: CANnabis and Adolescents: effect of a Brief Intervention on their Consumption. Study protocol for a randomized controlled trial. Trials. 2014;15(1):40.

44. Bahadoor K, Rude M, Picard-Bernard V, Marty L, Vorilhon P, Laporte C. Adolescent consumers of cannabis and general practitioners: how to communicate? Eur J Gen Pract. 2011;17(1):35-57.

45. Legleye S, Piontek D, Kraus L. Psychometric properties of the Cannabis Abuse Screening Test (CAST) in a French sample of adolescents. Drug Alcohol Depend. 2011;113(2-3):229-235.

46. Braunholtz DA, Edwards SJ, Lilford RJ. Are randomized clinical trials good for us (in the short term)? Evidence for a trial effect. J Clin Epidemiol. 2001;54(3):217-224.

47. Verbeke G, Molenberg G. Linear Mixed Models for Longitudinal Data. New York, NY: Springer-Verlag; 2000.

48. Rothman KJ. No adjustments are needed for multiple comparisons. Epidemiology. 1990;1(1):43-46.

49. Feise RJ. Do multiple outcome measures require $p$-value adjustment? BMC Med Res Methodol. 2002;2:8.

50. Lin LI. A concordance correlation coefficient to evaluate reproducibility. Biometrics. 1989;45(1):255-268.

51. McCambridge J, Kypri K. Can simply answering research questions change behaviour? Systematic review and meta analyses of brief alcohol intervention trials. PLOS ONE. 2011;6(10):e23748.

52. Smelt AFH, van der Weele GM, Blom JW, Gussekloo J, Assendelft WJJ. How usual is usual care in pragmatic intervention studies in primary care? An overview of recent trials. Br J Gen Pract. 2010;60(576):e305-e318.

53. Beck F, Guignard R, Richard J-B, Tovar M-L, Spilka S. Les niveaux d'usage des drogues en France en 2010. OFDT (Observatoire Français des Drogues et Toxicomanies). Tendances. 2011;(76):1-6.

54. Moyer A, Finney JW, Swearingen CE, Vergun P. Brief interventions for alcohol problems: a meta-analytic review of controlled investigations in treatment-seeking and non-treatment-seeking populations. Addiction. 2002;97(3):279-292.

55. World Health Organization. Brief intervention. The ASSIST-Linked Brief Intervention for Hazardous and Harmful Substance Use: Manual for Use in Primary Care. Geneva, Switzerland: World Health Organization; 2010.

56. Volkow ND, Baler RD, Goldstein RZ. Addiction: pulling at the neural threads of social behaviors. Neuron. 2011;69(4):599-602.

57. Page MJ, French SD, McKenzie JE, O'Connor DA, Green SE. Recruitment difficulties in a primary care cluster randomised trial: investigating factors contributing to general practitioners' recruitment of patients. BMC Med Res Methodol. 2011;11(1):35.

58. Yarnall KSH, Pollak KI, Østbye T, Krause KM, Michener JL. Primary care: is there enough time for prevention? Am J Public Health. 2003; 93(4):635-641.

59. Williams RL, Stange K, Phillips WR, et al. Encouraging innovation, unintended consequences, and group-level research. Ann Fam Med. 2013;11(3):200-202.

60. Hilbink M, Voerman G, van Beurden I, Penninx B, Laurant M. A randomized controlled trial of a tailored primary care program to reverse excessive alcohol consumption. J Am Board Fam Med. 2012;25(5):712-722.

61. Shaw EK, Ohman-Strickland PA, Piasecki A, et al. Effects of facilitated team meetings and learning collaboratives on colorectal cancer screening rates in primary care practices: a cluster randomized trial. Ann Fam Med. 2013;11(3):220-228. 